\title{
Comparative Study of Oral Clonidine Versus Gabapentin as Premedication for Anxiolysis, Sedation and Attenuation of Pressor Response to Laryngoscopy and Tracheal Intubation
}

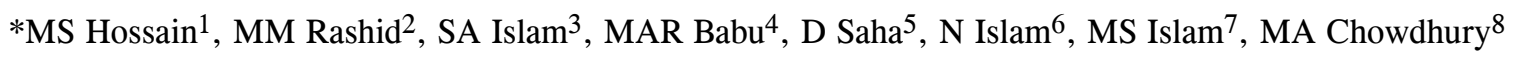 \\ ABSTRACT
}

Background and Aims: We conducted a prospective, randomized, double-blind and controlled trial to compare the effects of oral clonidine and gabapentin as premedication in obtunding hemodynamic response to laryngoscopy and intubation in normotensive patients undergoing elective surgery. We also compared the preoperative anxiety and sedation status between these two drugs.

Materials and Methods: A total of 60 patients of American Society of Anesthesiologists (ASA) physical status I, aged $20-50$ years of either sex enrolled in the study were randomly divided into two groups of 30 each. Group A patients received oral clonidine $200 \mathrm{mcg}$ and Group B patients received oral gabapentin $900 \mathrm{mg}, 90$ minutes prior to induction of anesthesia. The heart rate, systolic blood pressure, diastolic blood pressure and mean arterial pressure were observed and recorded pre and post endotracheal intubation. Anxiety and sedation score were noted after 60 minutes of oral administration of drug as well as before induction of anesthesia.

Results: Both groups were matched for age, sex, weight and intubation time. Anxiety score and sedation score before induction were significantly better in clonidine group as compared with gabapentin group. Also oral clonidine attenuated the increase in heart rate, systolic blood pressure, diastolic blood pressure and mean arterial pressure better than oral gabapentin $(\mathrm{p}<0.05)$.

Conclusion: Oral clonidine provided good attenuation of hemodynamic response to laryngoscopy and intubation as compared with oral gabapentin. Also clonidine is better agent as anxiolytic and sedative than gabapentin.

Key Words: Clonidine, gabapentin, laryngoscopy, endotracheal intubation, anxiety, sedation.

\section{Introduction}

The aim of anesthesiologist is not only to ensure a smooth induction and intubation but also to ensure an uneventful postoperative period. Laryngoscopy and tracheal intubation is a strong stimulus for cardiovascular system under light anesthesia. ${ }^{1}$ The magnitude of response is great with increasing force and duration of laryngoscopy. The elevation of arterial pressure typically starts within 5 seconds of laryngoscopy, peaks in 1-2 minutes and returns to control level within 5 minutes. ${ }^{1}$ Such hemodynamic changes can result in myocardial ischemia, specially in patients with cardiovascular disease. ${ }^{2}$ Deepening of anesthesia ${ }^{3}$, lignocaine spray ${ }^{4}$ or intravenous ${ }^{5}$, sodium nitroprusside ${ }^{6}$, nitroglycerine ${ }^{7}$, hydralazine ${ }^{8}$,

${ }^{1}$ Dr. Muhammad SazzadHossain, Associate Professor and HOD, Anesthesiology, National Institute of ENT, Dhaka, Bangladesh

${ }^{2}$ Dr. Mohammad Mamunur Rashid, Junior Consultant, Anesthesiology, National Institute of ENT, Dhaka, Bangladesh

${ }^{3}$ Dr. Syed Ariful Islam, Medical Officer, Anesthesiology, National Institute of ENT, Dhaka, Bangladesh

${ }^{4}$ Dr. Md. Anisur Rahman Babu, Medical Officer, National Institute of ENT, Dhaka, Bangladesh

${ }^{5}$ Dr. DevashisSaha, Research Officer, National Institute of ENT, Dhaka, Bangladesh

${ }^{6}$ Dr. Nadia Islam, Associate Professor, Pharmacology, Anwer Khan Modern Medical College, Dhaka, Bangladesh

${ }^{7}$ Dr. Md. Sirajul Islam, Assistant Professor, Anaesthesiology, Anwer Khan Modern Medical College, Dhaka, Bangladesh

${ }^{8}$ Prof. Dr. M. Alamgir Chowdhury, Professor, ENT Head \& Neck Surgery, Anwer Khan Modern Medical College, Dhaka, Bangladesh

*Corresponding Author

Date of submission: 07.03.2018, Date of acceptance: 17. 05.2018

AKMMC J 2018; 9(2) : 131-136 
beta blocker ${ }^{9}$, calcium channel blocker ${ }^{10}$, gabapentin, pregabalin, alpha2 agonists ${ }^{11,12,13}$ as clonidine and dexmedetomidine, opioids as alfentanyl $^{14}$, fentanyl ${ }^{15}$, remifentany ${ }^{16}$ have traditionally been used as preoperative medication to eliminate or to suppress the stress response to laryngoscopy and intubation. Clonidine is an alpha2 adrenergic agonist, stimulates alpha2A subtype of alpha2 adrenergic receptors in the brain stem resulting in a reduction in sympathetic outflow from central nervous system thus causing lowering of arterial pressure by an effect on both cardiac output and peripheral resistance. By its central sympathetic action, it tends to attenuate the hemodynamic response to any surgical nociceptive stimulus and to improve overall peri-anesthetic cardiovascular stability. ${ }^{17}$

Gabapentin is aminomethyl cyclohexane acetic acid, is structural analogue of neurotransmitter, gamma amino butyric acid (GABA) was introduced in 1993 as an adjunct antiepileptic drug for the treatment of refractory partial seizure. ${ }^{18}$ It was shown to be effective in treating postherpetic neuralgia, other neuropathic pain, post poliomyelitis neuropathy, reflex sympathetic dystrophy, diabetic neuropathy and it has antinociceptive, antihyperalgesic and antiallodynic properties. ${ }^{19}$ More recently, it has been used to attenuate the stress response to direct laryngoscopy and intubation. The mechanism by which gabapentin attenuates the pressor response to laryngoscopy and intubation is unknown. The drug inhibits membrane bound voltage gated calcium channels, thus acting in a manner similar to calcium channel blockers. ${ }^{20}$ Both clonidine and gabapentin have certain adverse effects inherent their structure. Most common side effects with clonidine are dry mouth, sedation, hypotension and bradycardia. ${ }^{14}$ The most frequent side-effects reported with gabapentin are somnolence, dizziness fatigue, headache tremors and nausea. ${ }^{21}$

In view of these observations, the present study was designed to evaluate the efficacy of oral clonidine (200 mcg) versus oral gabapentin (900 mg) premedication for anxiety and sedation status, blunting the heart rate variability as well as pressor response to direct laryngoscopy and intubation.

\section{Materials \& Methods}

It was a randomized controlled double blind study conducted in National Institute of ENT (NIENT) Dhaka, during the period of February and March 2018. After having obtained written informed consent from all 60 patients of either sex, aged between 20 and 50 years, belonging to ASA physical status class I, undergoing elective surgery under general anesthesia with endotracheal intubation were included. Patients with anticipated difficult intubation, more than one attempts of intubation, hypertension, hepatic or renal insufficiency, obesity and asthma were excluded from the study. Preanesthetic evaluation was done in all patients. The patients enrolled were randomly assigned into two equal groups of 30 patients each.

Clonidine group (Group A): Where patients received oral clonidine $200 \mathrm{mcg}, 90$ minutes prior to induction of anesthesia with a sip of water.

Gabapentin group (Group B): Where patients received oral gabapentin $900 \mathrm{mg}, 90$ minutes prior to induction of anesthesia with a sip of water.

Routine pre-anesthesia evaluation was carried out in all patients a day prior to the scheduled procedure. The patients and the concerned anesthesiologists were kept blinded to the group they were assigned. However, the investigator assessing the outcome was not blinded.

On arrival of the patient in the operating room, noninvasive blood pressure, electrocardiogram and pulse oximeter were attached. Base line values for pulse rate, systolic, diastolic and mean arterial blood pressure and arterial oxygen saturation were measured and recorded. The patients were kept nil per oral from the midnight before surgery. After securing the intravenous access premedication was done with intravenous fentanyl $2 \mathrm{mg}$ per $\mathrm{kg}$ body weight. Induction of anesthesia was done with a titrated dose of intravenous propofol after 3 minutes pre oxygenation. Vecuronium $0.1 \mathrm{mg} / \mathrm{kg}$ body weight was given for muscle relaxation. After 3 minutes of assisted ventilation the trachea was intubated with a single use high volume low pressure cuffed polyvinyl chloride endotracheal tube 7.5 and $7.0 \mathrm{~mm}$ internal diameter for male and female 
patients respectively. Position of ETT was confirmed and cuff was inflated with just enough room air to prevent audible leak then secured the endotracheal tube. General anesthesia was maintained as standard procedure with halothane, nitrous oxide, oxygen and vecuroniumas required. Patients were reversed as usual at the end of operation.

\section{Anxiety score Sedation score}

0: Patient quiet and comfortable 1: Wide awake

1: Patient uneasy 2: Sleeping comfortably but responding to

verbal command

2: Patient worried or anxious 3: Deep sleep but arousable

3: Patient very worried or very upset 4: Deep sleep but not arousable

4: patient frightened or terrified

Anxiety score and sedation score were recorded at base line and before induction of anesthesia. Hemodynamic parameters were noted just before the oral drug administered and after 90 minutes, before induction of anesthesia and just before intubation. Thereafter heart rate, systolic blood pressure, diastolic blood pressure and mean arterial pressurewererecoded at $1 \mathrm{~min}, 3 \mathrm{~min}, 5 \mathrm{~min}$ and 10 min after intubation. ECG was continuously monitored for any dysrhythmias during this period. Duration of laryngoscopy and endotracheal intubation was also recorded. Side effects pertaining to clonidine and gabapentin were noted preoperatively as well as post-operatively.

\section{Statistical Analysis}

At the end of the study data was compiled and analyzed using unpairedt- test for quantitative data and for non-quantitative data and association between groups with respecttovarious characteristics Chi-squire test was applied. A $\mathrm{p}<0.05$ was considered statistically significant.

\section{Results}

Table - I shows the distribution of age, weight and sex in two groups, which were comparable statistically.

Anxiety score and sedation score were compared before and after the administration of drugs. The difference was statistically significant $(p<0.05)$ in both the groups Table II and Table III.

However,anxiety score and sedation score were significantly better in clonidine (group A) as compared with gabapentin (group B) $\mathrm{p}<0.05$ Table IV and Table V.

Hemodynamic parameters as heart rate and mean arterial pressure were shown in Table VI and Table VII. Heart rate (Table VI) in clonidine (group A) remained below base line at all times except at 1 minute following intubation when transient rise was observed. Whereas in gabapentin (group B) the heart rate rise persisted until the end of study period and was statistically significant at all times as compared to group A $(\mathrm{p}<0.05)$.

Similarly mean arterial pressure(Table VII) also attenuated in group A and it remained below baseline throughout the study period. This fall in MAP was significant but did not warrant any active intervention. In group B also fall in MAP was observed at all times except at 1 minute following intubation when rise in MAP was observed, which was statistically significant $(\mathrm{p}<0.05)$.

Side-effects pertaining to clonidine and gabapentin were noted pre- and post-operatively. $46 \%$ of the patients in group A complained of dry mouth preoperatively and post-operatively andbradycardia observed in $3 \%$ cases, which did not warrant any treatment. Similarly, in group B there were minor complaints of headache, drowsiness and dizziness.

Table-I: Comparison of demographic data between the two groups

\begin{tabular}{lccc}
\hline Parameters & Group A $(\mathbf{n}=30)$ & Group B $(\mathbf{n}=30)$ & $\mathbf{p}$ value \\
\hline $\begin{array}{l}\text { Age in } \\
\text { years }(\text { mean } \pm \text { SD })\end{array}$ & $34.51 \pm 6.43$ & $35.72 \pm 5.86$ & $\mathrm{p}>0.05$ \\
$\begin{array}{l}\text { Weight in kg } \\
(\text { mean } \pm \text { SD })\end{array}$ & $56.83 \pm 7.48$ & $55.63 \pm 8.14$ & $\mathrm{p}>0.05$ \\
\begin{tabular}{l} 
Sex (male/female) \\
\hline
\end{tabular} & $16 / 14$ & $15 / 15$ & $\mathrm{p}>0.05$ \\
\hline
\end{tabular}


Table-II: Distribution of anxiety scorewithin the two groups

\begin{tabular}{lcccccc}
\hline Group & 0 & 1 & 2 & 3 & 4 & p value \\
\hline Group A (n=30) & & & & & & \\
Base line (\%) & $6(20 \%)$ & $24(80 \%)$ & 0 & 0 & 0 & $\mathrm{p}<0.05$ \\
Beforeinduction (\%) & $26(86.6 \%)$ & $4(13.34 \%)$ & 0 & 0 & 0 & \\
Group B (n=30) & & & & & & \\
Base line (\%) & $9(30 \%)$ & $21(70 \%)$ & 0 & 0 & 0 & \\
Before induction (\%) & $19(63.33 \%)$ & $11(36.66 \%)$ & 0 & 0 & 0 & $\mathrm{p}<0.05$ \\
\hline
\end{tabular}

Table-III: Distribution of sedation score within the two groups

\begin{tabular}{lccccc}
\hline Group & 1 & 2 & 3 & 4 & p value \\
\hline Group A (n=30) & & & & & \\
Base line (\%) & $27(90 \%)$ & $3(10 \%)$ & 0 & 0 & $\mathrm{p}<0.05$ \\
Before induction (\%) & $8(26.66 \%)$ & $22(73.33 \%)$ & 0 & \\
Group B (n=30) & & & & & \\
Base line (\%) & $26(86.66 \%)$ & $4(13.33 \%)$ & 0 & \\
Before induction (\%) & $22(73.33 \%)$ & $14(46.66 \%)$ & 0 & $\mathrm{p}<0.05$
\end{tabular}

Table-IV: Comparison of anxiety score in-between the two groups before induction

\begin{tabular}{lcccccc}
\hline Group & 0 & 1 & 2 & 3 & 4 & p value \\
\hline Group A (n=30) (\%) & $26(86.6 \%)$ & $4(13.34 \%)$ & 0 & 0 & 0 & $\mathrm{p}<0.05$ \\
Group B (n=30) (\%) & $19(63.33 \%)$ & $11(36.66 \%)$ & 0 & 0 & 0 & \\
\hline
\end{tabular}

Table-V: Comparison of sedation score in-between the two groups before induction

\begin{tabular}{|c|c|c|c|c|c|}
\hline Group & 1 & 2 & 3 & 4 & 5 \\
\hline Group A $(n=30) \%$ & $8(26.66 \%)$ & $22(73.33 \%)$ & 0 & 0 & $\mathrm{p}<0.05$ \\
\hline Group B ( $\mathrm{n}=30 \%)$ & $22(73.33 \%)$ & $14(46.66 \%)$ & 0 & 0 & \\
\hline
\end{tabular}

Table-VI: Changes in heart rate compared with base line in two groups at various time intervals (percentage)

\begin{tabular}{lccccc}
\hline Groups & $\begin{array}{c}\text { Before } \\
\text { induction }\end{array}$ & $\begin{array}{c}\text { Just before } \\
\text { intubation }\end{array}$ & $\begin{array}{c}\mathbf{1} \text { min } \\
\text { after ETIafter ETIafter ETI }\end{array}$ & $\mathbf{3}$ min & $\mathbf{5}$ min \\
& -4.12 & -6.78 & +6.52 & -2.14 & -9.63 \\
Group A (n=30) & $\mathrm{p}<0.05$ & $\mathrm{p}<0.05$ & $\mathrm{p}<0.05$ & $\mathrm{p}>0.05$ & $\mathrm{p}<0.05$ \\
p value & -1.17 & -1.84 & +11.82 & +6.96 & +1.12 \\
Group B ( $=30)$ & $\mathrm{p}>0.05$ & $\mathrm{p}>0.05$ & $\mathrm{p}<0.05$ & $\mathrm{p}<0.05$ & $\mathrm{p}>0.05$ \\
P value & $\mathrm{p}<0.05$ & $\mathrm{p}<0.05$ & $\mathrm{p}<0.05$ & $\mathrm{p}<0.05$ & $\mathrm{p}<0.05$ \\
p value ( inter group) & $\mathrm{n}$ & & & & \\
\hline
\end{tabular}

Table-VII: Changes in mean arterial pressure compared with base line in two groups at various time intervals (percentage)

\begin{tabular}{lccccc}
\hline Groups & $\begin{array}{c}\text { Before } \\
\text { induction }\end{array}$ & $\begin{array}{c}\text { just before } \\
\text { intubation }\end{array}$ & $\begin{array}{c}\mathbf{1} \text { min } \\
\text { after ETIafter ETIafter ETI }\end{array}$ & $\mathbf{3}$ min & $\mathbf{5}$ min \\
\hline Group A ( $=30)$ & -8.74 & -11.64 & -1.94 & -12.43 & -15.47 \\
p value & $\mathrm{p}<0.05$ & $\mathrm{p}<0.05$ & $\mathrm{p}>0.05$ & $\mathrm{p}<0.05$ & $\mathrm{p}<0.05$ \\
Group B ( $=30)$ & -5.83 & -8.68 & +8.17 & -5.36 & -7.82 \\
p value & $\mathrm{p}<0.05$ & $\mathrm{p}<0.05$ & $\mathrm{p}<0.05$ & $\mathrm{p}<0.05$ & $\mathrm{p}<0.05$ \\
p value ( inter group) & $\mathrm{p}>0.05$ & $\mathrm{p}>0.05$ & $\mathrm{p}<0.05$ & $\mathrm{p}<0.05$ & $\mathrm{p}<0.05$ \\
\hline
\end{tabular}

\section{Discussion}

The sympathoadrenal activation associated with laryngoscopy and endotracheal intubation causes the rise in arterial blood pressure, tachycardia and dysrhythmias. The achievement of a smooth induction with minimal reflex hemodynamic response during laryngoscopy and endotracheal intubation remains an important anesthetic goal. Several strategies have been evolved to blunt this undesirable response, but each method has its own advantage and disadvantage.

Clonidine and gabapentin are drugs under intense investigation as an adjunct to anesthesia in various forms. ${ }^{21}$ Clonidine originally introduced as antihypertensive drug, has analgesic, sedative and anxiolytic properties. It improves the quality of induction, maintenance and recovery of anesthesia. By its central sympatholytic action, it tends to attenuate the hemodynamic response to any surgical nociceptive stimulus and improve overall perianesthetic cardiovascular stability. ${ }^{17}$ Prevention of tachycardia in response to laryngoscopy and endotracheal intubation and the slowing of heart rate induced by clonidine share a complex mechanism. It consists of different components, centrally the activation of alpha 2 adrenoceptors causes both a reduction in peripheral sympathetic tone and an increase of vagally induced reflex bradycardia. Similarly, gabapentin most recently has been evaluated as an analgesic, anti-hyperalgesic when used perioperatively. Role of gabapentin in obtunding hemodynamic response has been highlighted by Fassoulaki et al and Memis et al. ${ }^{21,22}$ We evaluated and compared oral clonidine and 
gabapentin in abolishing the hemodynamic response to laryngoscopy and endotracheal intubation.

The effect of clonidine 200mcg on MAP and HR in our study was similar to the observation of Ravel and Mehta. ${ }^{23}$ Fassoulaki et al. ${ }^{22}$ observed that higher dose of gabapentin $(1600 \mathrm{mg})$ had no effect on HR and MAP at 0-24 hours after operation but Memis et al. observed complete attenuation od HR and MAP with $800 \mathrm{mg}$ gabapentin when given orally 1 hour before surgery. Marashi et al. ${ }^{24}$ after comparative evaluation of two drugs reached an inference that both clonidine and gabapentin are equally effective in attenuating BP response to laryngoscopy and intubation.

We observed that both clonidine and gabapentin showed anxiolysis and sedation in a significant proportion of subjects. The anxiolytic and sedative effect was significantly more with clonidine than gabapentin. Our results were similar to the study of Faheim et al. ${ }^{25}$ who used clonidine $300 \mathrm{mcg}$ and gabapentin $600 \mathrm{mg}$.

\section{Conclusion}

Oral clonidine $200 \mathrm{mcg}$ when given 90 minutes before anesthesia is better attenuator among the two drugs (gabapentin $900 \mathrm{mg}$ orally) studied over here to attenuate the cardiovascular responses to laryngoscopy and endotracheal intubation. Clonidine also provided better sedation and anxiolysis when compared with gabapentin.

Conflict of interest: All the authors hereby declare that they have no conflicts of interest, financial or otherwise, with respect to publication of the submitted manuscript.

\section{References}

1. Henderson J. Airway management in adult In: Ronld D, Miller, editors. Miller's Anesthesia. $7^{\text {th }}$ ed. chapter 50. Philadelphia: Churchill Livingstone Elsevier; 2010. pp. 1573-609.

2. Rose DK, Cohen MM. The airway: Problems and predictions in 18500 patients. Can J Anesth. 1994; 41: 372-83.

3. King BD. Reflex circulatory responses to direct laryngoscopy and tracheal intubation performed during general anesthesiology. 1951; 12: 556-66.
4. Stoelting RK, Peterson C. Circulatory changes during direct laryngoscopy and tracheal intubation: influence of duration of laryngoscopy with or without prior lidocaine. Anesthesiology. 1977; 47: 381.

5. Hamill James F. Lidocaine before endotracheal Intravenous or intubation: Laryngotracheal? Anesthesiology. 1981; 55: 578-582.

6. Stoelting RK. Attenuation of blood pressure response to laryngoscopy and tracheal intubation with sodium nitropruside. Anesth Analg. 1979; 58: 116-19.

7. Elkayam, Wilbert, Aronow S. Glycerol trinitrate ointment and isosorbibedinitrate: review of their pharmacological properties and therapeutic use. Drugs. 1982; 23: 165.

8. Davies MJ, Cronin KD, Cowie RW. The prevention of hypertension at intubation. A controlled study of intravenous hydralazine on patients undergoing intracranial surgery. Anesthesia. 1981; 36: 147-51.

9. Cucchiara RF, Benefiel DJ, Matteo RS, et al. Evaluation of esmolol in controlling increases in heart rate and blood pressure during endotracheal intubation in patients undergoing carotid end-arterectomy. Anesthesiology.1986; 65: 528-31.

10. PuriGD, Batra YK. Effect of nifedipine on cardiovascular responses to laryngoscopy and intubation. Br J Anesth.1988; 60: 579-81.

11. Sulaiman S, Kartheyan RB, Vakamudi M, et al. The effects of dexmedetomidine on attenuation of stress response to endotracheal intubation in patients undergoing elective off-pump coronary artery bypass grafting. Ann Card Anesth 2012; 15: 39-43.

12. Keniya VM, Ladi S, Naphadi R. Dexmedetomidine attenuates perioperative anesthetic requirement. Indian J Anesth. 2011; 55: 352-7.

13. Manda F, Koner $\mathrm{O}$, Sayin $\mathrm{M}$, et al. Dexmedetomidine as an adjunct to anesthetic induction to attenuate hemodynamic response to endotracheal intubation in patients undergoing fasttrak CABG. Ann Card Anesth 2010; 13: 16-21. 
14. Miller DR, Martineau RJ, O'Brien $\mathrm{H}$, et al. Effects of alfentanyl on the hemodynamic and catacholamine response to tracheal intubation. Anesth Analg. 1993; 76: 1040-6.

15. Ghignone M, Quintin L, Duke PC, et al. Effects of clonidine on narcotic requirements and hemodynamic response during induction of fentanyl anesthesia and endotracheal intubation. Anesthesiology.1986; 64: 36-42.

16. O'Hare R, Mcatamney D, Mirakhur RK, et al. Bolus dose remifentanyl for control of hemodynamic response to tracheal intubation during rapid sequence induction of anesthesia. Br J Anesth. 1999; 82: 283-5.

17. Westfall TC, Westfall DP. Adrenergic agonist and antagonist. In: Bruton LL, LazoJS, Parker JS, editors. Goodman and Gillman's the pharmacological Basis of Therapeutics. $11^{\text {th }}$ ed. USA: McGraw- Hill: 2006. pp 255-6.

18. Turan A, Kaya G, Karamanlioglu B, et al. Effect of oral gabapentin on post-operative analgesia. Br J Anesth. 2006; 96: 242-6.

19. Rose MA, Kam PC. Gabapentin: Pharmacology and its use in pain management. Anesthesia. 2002; 57: 451062.

20. Fassoulaki A, Melameni A, Paraskeva A, Petropoulos. Gabapentin attenuates the pressor responses to direct laryngoscopy and tracheal intubation. Br J anesth. 2006; 96: 769-73.
21. Memis D, Turan A, Karamanlioglu B, et al. Gabapentin reduces cardiovascular responses to laryngoscopy and tracheal intubation. Eur $\mathrm{J}$ Anesthesiol. 2006; 23: 686-90.

22. FassoulakiA, Melameni A, Paraskeva A, et al. Gabapentin attenuates the pressor response to direct laryngoscopy and tracheal intubation $\mathrm{Br} \mathrm{j}$ Anesth. 2006; 96: 769-73.

23. Ravel D, Mehta M. Oral clonidine premedication for attenuation of hemodynamic response tomlaryngoscopy and intubation Indian J Anesth. 2002; 46: 124-9.

24. Marashi SM, Ghafari MH, Salaiminia A. Attenuation of hemodynamic responses following laryngoscopy and intubationcomparetive assessment of clonidine and gabapentin premedication. Middle East $\mathrm{J}$ Anesthesiol. 2009; 20: 233-37.

25. Faheim SM, Hassanin M, Hafez AA. Gabapentin versus clonidine oral premedication for attenuation of pressor response to laryngoscopy and intubation Tanta Med Sci J. 2008; 3: 12-20. 